\section{Temporary Destocking of Pastures to aid Control of the Cattle Tick}

THE tick Boophilus microplus Can., is generally considered to be the most serious single cause of loss to the cattle industry in tropical Australia, contribut. ing to the death of many cattle in dry years. Present control measures are costly, and by placing undue reliance on frequent dipping are thought to have increased the tendency of ticks to become resistant to $\mathrm{BHC}$ and arsenic. A method involving only two or three dippings per year can be expected to reduce the difficulties of controlling strains of ticks resistant to these and newer acaricides. The results of the following 'pilot-scale' experiment carried out near Rockhampton, Queensland, emphasize the possibility of reducing the frequency of acaricidal treatment by destocking the pastures for periods which some cattle owners do not find inconveniently long.

Two herds of cattle were kept in adjoining comparable paddocks of approximately seventy-five acres. An equal number (10-14) of animals was present in each of the two herds at any one time. The 'control' herd was allowed access to the whole area of paddock $C$ continuously, whereas the experimental herd was alternated between the two halves, $A$ and $B$, of the other paddock, which was divided by an electric fence. The periods for which the $A$ or $B$ paddocks were destocked were based, after mid-November 1953, on observations made in the district on the time taken from the date of drop of a replete female tick to the death of its larval progeny (Wilkinson, unpublished data). Fig. 1 shows infestations of adult ticks, exceeding $0.5 \mathrm{~cm}$. in length, on the two herds, the numbers with arrows indicating occasions on which the animals were sprayed with DDT preparation ( 1 per cent $p, p^{\prime}$-isomer). It will be seen that, after the beginning of February 1954, infestations of the cattle moved to previously destocked pastures remained low. A few ticks continued to occur on the cattle, and this was considered a desirable feature, because the cattle would be regularly re-infested with Babesia carried by the larvæ and thus retain their immunity to 'redwater' fever'2.

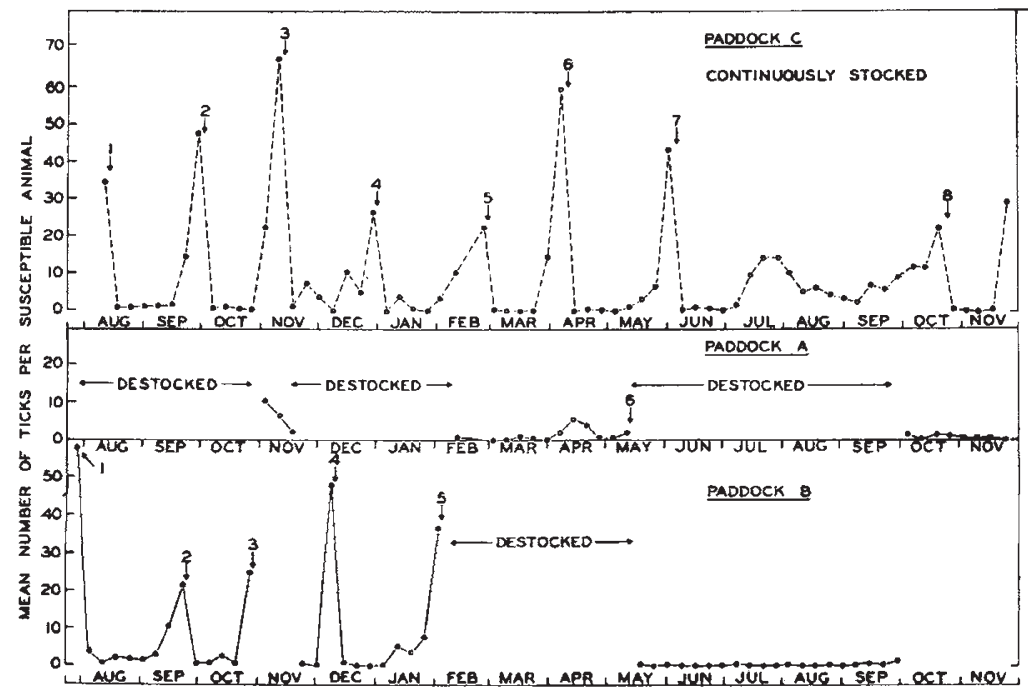
Fig. 1. Comparison of infestations of cattle on a continuously stocked and a pasture
spelling paddock. Counts of female ticks, $0.5 \mathrm{~cm}$. and upwards in length, on the right side of the cattle
Destocking of pastures has been practised frequently during tick eradication campaigns, but no experiment on destocking as a control measure has hitherto been described. A fuller account of this work and its application to Queensland conditions will be published elsewhere.

Veterinary Parasitology Laboratory,

\section{P. R. WILKINSON}

Division of Entomology,

Commonwealth Scientific and

Industrial Research Organization,

Yeerongpilly, Queensland.

${ }^{1}$ Hitchcock, L. F., Aust. J. Agric. Res., 4, 360 (1953).

${ }^{2}$ Legg, J., C.S.I.R. Aust. Pamphlet No. 56 (Melbourne, 1935),

\section{A New Acaricide, 2,4,5,4'-Tetrachlorodiphenylsulphone}

Läuger et al. ${ }^{1}$, Swingle ${ }^{2}$ and Browning et al. ${ }^{8}$ have stated that the insecticidal value of $p, p^{\prime}$-dichlorodiphenylsulphone is relatively low ; Läuger et al. ${ }^{1}$ state that diphenylsulphone and monochlorodiphenylsulphone are devoid of any insecticidal activity. On the other hand, Eaton ${ }^{4}$ found among various diphenyl compounds some substances with a sulphone link active against spider mites and their eggs; optimal acaricidal activity occurred with mono-p-chlorodiphenylsulphone ${ }^{5}$.

Diphenylsulphone and mono-p-chlorodiphenylsulphone are more or less phytocidal at active concentrations. We have now found that 2,4,5trichlorodiphenylsulphone (' $V \quad 17$ ') and 2,4,5,4'tetrachlorodiphenylsulphone ('Tedion $V 18$ ') possess strong acaricidal properties without phytocidal side. effects. As can be seen from Tables 1 and 2, the latter substance is more active on the eggs than any of the other compounds listed. As is the case with some newer specific acaricides now in use, such as $C P B S(p$. chlorophenyl-benzenesulphonate), $C P C B S$ ( $p$-chlorophenyl-p-chlorobenzenesulphonate) and $p$-chlorophenyl-p-chlorobenzylsulphide, 'Tedion $V$ 18' also shows activity on all stages except adult spider mites.

The various compounds were tested on Tetranychus urticae Koch on bean plants (Phaseolus). Potted bean plants with or without eggs were dipped in emulsions containing the active material. After the plants without eggs had dried, these were infected with adult females in order to obtain eggs on the dry residue. After two or three days the adults were removed. In order to evaluate the penetration of 'Tedion' into the leaf, leaves were treated on the upper side and infected with mites on the under side. Solutions and emul. sions containing 1,000 and 100 p.p.m. of active material caused in these circumstances a total kill of eggs and larvæ.

The phytotoxic properties of 'Tedion $V$ 18' were investigated on seedlings of Tropaeolum majus, cucumber, tomato, potato, broad bean (Vicia faba), French bean (Phaseolus vulgaris) and garden pea (Pisum sativum). The plants were thoroughly sprayed with $0 \cdot 3,1 \cdot 0$ and $3 \cdot 0$ per cent of active material, 